\title{
The Effect of Different Cadence on Paddling Gross Efficiency and Economy in Stand-Up Paddle Boarding
}

\author{
Arkaitz Castañeda-Babarro ${ }^{1,2}{ }^{\mathbb{D}}$, Jordan Santos-Concejero ${ }^{3}{ }^{(0)}$, Aitor Viribay ${ }^{4}$, \\ Borja Gutiérrez-Santamaría ${ }^{1}$ and Juan Mielgo-Ayuso ${ }^{5, *}$ (])
}

1 Health, Physical Activity and Sports Science Laboratory, Department of Physical Activity and Sports, Faculty of Psychology and Education, University of Deusto, 48007 Bizkaia, Spain; arkaitz.castaneda@deusto.es (A.C.-B.); borjagutierrez@deusto.es (B.G.-S.)

2 Physiotherapy Department, Institute of Biomedicine (IBIOMED), University of Leon, Campus de Vegazana, 24071 Leon, Spain

3 Department of Physical Education and Sport, Faculty of Education and Sport, University of the Basque Country UPV/EHU, 01007 Vitoria-Gasteiz, Spain; jordan.santos@ehu.eus

4 Glut4Science, Physiology, Nutrition and Sport, 01004 Vitoria-Gasteiz, Spain; aitor@glut4science.com

5 Department of Biochemistry, Molecular Biology and Physiology, Faculty of Health Sciences, University of Valladolid, 42004 Soria, Spain

* Correspondence: juanfrancisco.mielgo@uva.es; Tel.: +34-975-129-187

Received: 13 June 2020; Accepted: 5 July 2020; Published: 7 July 2020

\begin{abstract}
Background: Due to the importance of energy efficiency and economy in endurance performance, it is important to know the influence of different paddling cadences on these variables in the stand-up paddleboarding (SUP). The purpose of this study was to determine the effect of paddling at different cadences on the energy efficiency, economy, and physiological variables of international SUP race competitors. Methods: Ten male paddlers (age $28.8 \pm 11.0$ years; height $175.4 \pm 5.1 \mathrm{~m}$; body mass $74.2 \pm 9.4 \mathrm{~kg}$ ) participating in international tests carried out two test sessions. In the first one, an incremental exercise test was conducted to assess maximal oxygen uptake and peak power output (PPO). On the second day, they underwent 3 trials of 8 min each at $75 \%$ of PPO reached in the first test session. Three cadences were carried out in different trials randomly assigned between $45-55$ and 65 strokes- $\mathrm{min}^{-1}(\mathrm{spm})$. Heart rate (HR), blood lactate, perceived sense of exertion (RPE), gross efficiency, economy, and oxygen uptake $\left(\mathrm{VO}_{2}\right)$ were measured in the middle (4-min) and the end (8-min) of each trial. Results: Economy (45.3 $\pm 5.7 \mathrm{KJ} \cdot \mathrm{l}^{-1}$ at $45 \mathrm{spm}$ vs. $38.1 \pm 5.3 \mathrm{KJ} \cdot \mathrm{l}^{-1}$ at $\left.65 \mathrm{spm} ; p=0.010\right)$ and gross efficiency $(13.4 \pm 2.3 \%$ at $45 \mathrm{spm}$ vs. $11.0 \pm 1.6 \%$ at $65 \mathrm{spm} ; p=0.012)$ was higher during de $45 \mathrm{spm}$ condition than $65 \mathrm{spm}$ in the 8-min. Respiratory exchange ratio (RER) presented a lower value at 4-min than at 8-min in $55 \mathrm{spm}$ (4-min, $0.950 \pm 0.065$ vs. 8-min, $0.964 \pm 0.053)$ and $65 \mathrm{spm}$ cadences (4-min, $0.951 \pm 0.030$ vs. 8-min, $0.992 \pm 0.047$; $p<0.05) . \mathrm{VO}_{2}, \mathrm{HR}$, lactate, and RPE were lower $(p<0.05)$ at $45 \mathrm{spm}\left(\mathrm{VO}_{2}, 34.4 \pm 6.0 \mathrm{~mL} \cdot \mathrm{kg}^{-1} \cdot \mathrm{min}^{-1}\right.$; $\mathrm{HR}, 161.2 \pm 16.4$ beats. $\mathrm{min}^{-1}$; lactate, $3.5 \pm 1.0 \mathrm{mmol} \cdot \mathrm{l}^{-1}$; RPE, $\left.6.0 \pm 2.1\right)$ than at $55 \mathrm{spm}\left(\mathrm{VO}_{2}\right.$, $38.6 \pm 5.2 \mathrm{~mL} \cdot \mathrm{kg}^{-1} \cdot \mathrm{min}^{-1}$; HR, $168.1 \pm 15.1$ beats $\cdot \mathrm{min}^{-1}$; lactate, $4.2 \pm 1.2 \mathrm{mmol} \cdot \mathrm{l}^{-1}$; RPE, $6.9 \pm 1.4$ ) and $65 \mathrm{spm}\left(\mathrm{VO}_{2}, 38.7 \pm 5.9 \mathrm{~mL} \cdot \mathrm{kg}^{-1} \cdot \mathrm{min}^{-1} ; \mathrm{HR}, 170.7 \pm 13.0\right.$ beats $\cdot \mathrm{min}^{-1} ; 5.3 \pm 1.8 \mathrm{mmol} \cdot \mathrm{l}^{-1} ; \mathrm{RPE}$, $7.6 \pm 1.4)$ at 8 -min. Moreover, lactate and RPE at $65 \mathrm{spm}$ was greater than $55 \mathrm{spm}(p<0.05)$ at 8 -min. Conclusion: International male SUP paddlers were most efficient and economical when paddling at $45 \mathrm{spm}$ vs. 55 or $65 \mathrm{spm}$, confirmed by lower RPE values, which may likely translate to faster paddling speed and greater endurance.
\end{abstract}

Keywords: economy; efficiency; stand up paddle; cadences; performance 


\section{Introduction}

Stand up paddleboarding (SUP) is a mixture of surfing and paddling [1], which has seen a significant increase in its number of practitioners. [2]. SUP involves propelling oneself with a long single-blade paddle using either side [3] on top of a board, which is longer, thicker, and wider than traditional surfboards [4]. There are three types of competitions in SUP: techniques, surfing, and racing [5]. While surfing competitions involve performing the highest quantity and quality of maneuvers in the waves, technical competitions and races entail performing a distance in the shortest time possible, both on open water and on flat water. In races, the most common distances to be covered are usually around 4-10 km (6.21 miles), although there are much longer distances [5].

There are different internal and external factors that have been studied in other surfing sports, which may be applicable to SUP [6]. Performance in these is conditioned by general weather conditions, which may be reflected in currents, wind, or waves. It is important that competitors know how to read the sea and take advantage of its waves so that they can cover several meters without having to make any effort. To do so, they must modify their trajectory and adjust it to each situation. Regarding internal variables, due to the importance of catching the waves mentioned above, and the speed stimuli needed during competitions, having a well-developed anaerobic metabolism can prove to be a determining factor.

On the other hand, SUP athletes are characterized by having good dynamic balance, as well as great strength in the trunk muscles [4]. This isometric strength of the trunk muscles, added to that of the gluteus and legs, is fundamental in counteracting the rotation forces that occur while paddling [7]. Furthermore, it seems that a well-trained aerobic metabolism is of great importance in different types of race [8]. Related to these major aerobic requirements, efficiency and economy are important aspects of endurance performance. Some studies claim that efficiency may be a better predictor of aerobic performance compared to maximal oxygen uptake $\left(\mathrm{VO}_{2} \max \right)$ [9-11]. Conversely, other authors have shown that economy, defined as the energy demand at submaximal speeds, is one of the most discriminating factors of endurance performance, especially in athletes with similar $\mathrm{VO}_{2}$ max [12-17]. In this regard, Conley et al. [13] concluded that among highly trained and experienced runners of comparable capacity and similar $\mathrm{VO}_{2}$ max, running economy represents a large amount of the observed variation in performance over a $10 \mathrm{~km}$ run. While Mooses et al. [18] assert that economy is one of the factors explaining running performance, Bassett Jr et al. [19] claim that running economy and fractional utilization of $\mathrm{VO}_{2}$ max largely explains endurance performance.

Considering that this sport takes place in natural environments, with changing wind and waves, the paddling cadence during open sea SUP races may not be constant. Several studies in other sports have suggested that some cadences are more efficient than others [6,20-26]. In the case of cyclists and triathletes, Jacobs et al. [20] showed how lower cadences were more economical in trained subjects, while de Lucia et al. [21] obtained opposite results with world-class cyclists. In hand cycling, Kraaijenbrink et al. [25] obtained better efficiency values with low cadences than with high cadences, while Goosey et al. [26] comparing two crank lengths with two different cadences, obtained higher economy values with a short crank $(180 \mathrm{~mm})$ and higher cadence (85rev.min-1). With regard to running, Hafter et al. [23] after 6 weeks of training increased the cadence, although they managed to modify all the kinematic parameters, they did not manage to decrease the efficiency. Finally, with regard to traditional rowing, Aramendi et al. [24] recorded higher lactate and heart rates (HR) values at high cadences than at low cadences.

The question arises as to whether specific paddling cadences can be used, at $75 \%$ of PPO of the $\mathrm{VO}_{2}$ max, in order to improve efficiency and performance in SUP athletes. Thus, the main aim of this study was to analyze the influence of different paddling cadences: 45,55 , and 65 strokes-minute ${ }^{-1}$ (spm), on movement, gross efficiency and economy among elite competitive paddlers. Our hypothesis was that lower cadences would have better gross efficiency and economy compared to higher cadences. 


\section{Material and Methods}

\subsection{Participants}

Ten male international SUP race competitors with at least four years' competitive paddling experience were recruited for this study. Age, height, weight, anthropometric data, power test, and incremental test values of the participants are presented in Table 1. All participants were tested between 06/2019 and 08/2019, i.e., while they were during the competitive period of the 2019 season. The participants had undergone medical screening to ensure they were in good health and free from injury in the 12 months prior to research being conducted. Paddlers were fully informed of any risks associated with the experiments and provided with written informed consent to participate in the study, which was approved by the University of Deusto Ethics Committee (ref. ETK-13/18-19) in accordance with the latest version of the Declaration of Helsinki, Fortaleza (2013).

Table 1. Participants' age, body composition, and athletic performance characteristics $(n=10)$.

\begin{tabular}{ccc}
\hline Variable & Mean \pm SD & Range (Min-Max) \\
\hline Age $(\mathrm{y})$ & $28.8 \pm 11.0$ & $18.0-46.0$ \\
\hline Height $(\mathrm{cm})$ & $175.4 \pm 5.1$ & $167.0-186.5$ \\
\hline Body mass $(\mathrm{kg})$ & $74.2 \pm 9.4$ & $61.3-92.9$ \\
\hline Muscular mass $(\mathrm{kg})$ & $36.7 \pm 3.9$ & $30.5-44.0$ \\
\hline Muscular mass $(\%)$ & $49.6 \pm 2.4$ & $45.9-55.1$ \\
\hline Body fat $(\%)$ & $12.7 \pm 3.9$ & $6.7-17.9$ \\
\hline PPO in $10 \mathrm{~s}(\mathrm{~W})$ & $336.7 \pm 88.7$ & $210.0-528.0$ \\
\hline $\mathrm{VO}_{2}$ max $(\mathrm{mL} \cdot \mathrm{kg}$ & $45.2-57.8$ \\
\hline $\mathrm{HR}$ max $\left(\mathrm{beats} \cdot \mathrm{min}^{-1}\right)$ & $49.9 \pm 3.7$ & $164-207$ \\
\hline PPO at $\mathrm{VO}{ }_{2} \mathrm{max}(\mathrm{W})$ & $183.2 \pm 14.1$ & $120-190$ \\
\hline Relative $\mathrm{PPO}\left(\mathrm{W} \cdot \mathrm{kg}^{-1}\right)$ & $160.0 \pm 19.5$ & $1.7-2.8$ \\
\hline Muscle relative $\mathrm{PPO}\left(\mathrm{W} \cdot \mathrm{kg}^{-1}\right)$ & $2.2 \pm 0.3$ & $3.5-5.6$ \\
\hline
\end{tabular}

Data are expressed as mean \pm standard deviation. PPO, peak power output; HRmax, maximal heart rate; VO2 max, maximum oxygen uptake; $\mathrm{PO}$, power output.

\subsection{Experimental Trials}

All participants underwent two test sessions with a week's interval. On the first test day, an incremental exercise test was conducted to assess $\mathrm{VO}_{2}$ max and peak power output (PPO). These data were used to determine the intensity at which the participants should exercise in the second test session, which involved paddling at a constant sub-maximal intensity at 45,55 , and $65 \mathrm{spm}$ to study how the cadence influenced paddling gross efficiency. The tests with different cadences involved three trials of 8 minutes' (stage test) duration each, at $75 \%$ of $\mathrm{PPO}$ recorded in the $\mathrm{VO}_{2}$ max test. This intensity was selected to mimic the pace used during competitions [27]. The trials were $8 \mathrm{~min}$ long because it has been shown that this is a suitable duration for the purpose of evaluating gross efficiency and economy. [6,11]. There was a 10-min break between the trials. If during those $10 \mathrm{~min}$ the participant had not managed to descend from 100 beats $\mathrm{min}^{-1}$, rest time was increased until they were able to do so. To prevent an order effect, the three cadence trials $(45,55$, and $65 \mathrm{spm})$ were performed in a random sequence, and the paddling cadences selected for the study were based on peak cadence data obtained during a stress test by Schram et al. [4].

All paddle tests were performed on a modified ergometer (Ergo Vasa Swim, USA) [28] to ensure the same measurements in all tests. The $\mathrm{VO}_{2}$ max test was performed starting at $5 \mathrm{~W}$, increasing by $5 \mathrm{~W}$ every minute and up to volitional exhaustion level [8]. All athletes were allowed to alternate paddling on each side ad libitum, and participants were given feedback about their cadence, visual feedback via 
the computer monitor of the ergometer, and sound feedback via metronome. Athletes were considered to have achieved maximal performance, and therefore reached their $\mathrm{VO}_{2} \max$, when at least two of the following criteria were fulfilled [29]: I) a plateau in $\mathrm{VO}_{2}$ max, defined as an increase of less than $1.5 \mathrm{~mL} \cdot \mathrm{kg}^{-1} \cdot \mathrm{min}^{-1}$ in two consecutive workloads; II) RER $>1.15$; and III) maximal HR value (HRmax) $>95 \%$ of the age-predicted maximum (220 - age). PPO (in W) was calculated as follows, taking every second into account (Equation (1)) [12]:

$$
\mathrm{PPO}=\text { completed full intensity }(\mathrm{W})+((\text { second at final velocity } / 60 \mathrm{~s}) \times 5 \mathrm{~W})
$$

The ergometer was calibrated according to the manufacturer's recommendations prior to all tests. To ensure a complete recovery and that there was no change in performance levels obtained in the tests, the measurements were taken at one-week intervals. Participants were also asked not to do any strenuous exercise $24-48 \mathrm{~h}$ prior to the assessments, and to eat a high-carbohydrate diet prior to the evaluation sessions. To avoid any variations in performance due to changes in the time of day at which the tests were performed, all evaluations were conducted at the same time of day.

\subsection{Procedure}

On the first day, height $(\mathrm{cm})$ was obtained using a SECA 220 measuring rod (Hamburg, Germany), with precision to within $1 \mathrm{~mm}$. Body Mass (BM; kg), percentage of body fat, body muscle $(\mathrm{kg})$, and percentage of body muscle were measured using Inbody 770 (USA) within $0.1 \mathrm{~kg}$. An incremental VASA ergometer test (Vasa, Inc., Essex Junction, VT, USA) was used to assess the $\mathrm{VO}_{2}$ max, and expired gases were collected and analyzed using a calibrated continuous breath-by-breath gas exchange and ventilation measurements at the mouth (Ergostik, Geratherm Respiratory GmbH, Bad Kissingen, Germany). The metabolic cart was calibrated to manufacturer recommendations before every test session.

On the second day, mean $\mathrm{VO}_{2}$ and power output (PO) were computed during the last $30 \mathrm{~s}$ in minute 4 (4-min) and minute 8 (8-min) of each trial (45-55 and $65 \mathrm{spm})$. Economy was calculated according to the Moseley and Jeukendrup equation (Equation (2)) [30] where the economy $\left(\mathrm{KJ} \cdot \mathrm{L}^{-1}\right.$ ) equals the ratio between mean power output $(\mathrm{PO})$ and mean steady-state oxygen uptake $\left(\mathrm{L} \cdot \mathrm{min}^{-1}\right)$ :

$$
\text { Economy }=\mathrm{PO}(\mathrm{W}) / \mathrm{VO}_{2}\left(\mathrm{~L} \mathrm{~min}^{-1}\right)
$$

Participants' gross efficiency was assessed by calculating the amount of work completed relative to the amount of energy expended during each of the submaximal test stages, using the equation (Equation (3)):

$$
\text { Gross Efficiency } \%=\left[\text { work rate }(W) / \text { energy cost }\left(J^{-1}\right)\right] 100
$$

The energy consumed was calculated using the Weir equation [31] (Equation (4)):

$$
\mathrm{Kcal}=3.90 \mathrm{VO}_{2}(l)+1.10 \mathrm{VCO}_{2}(l)
$$

Kcal.min-1 was converted to $\mathrm{J} \cdot \mathrm{s}^{-1}$ to quantify energy cost, and energy output as a percentage of energy cost was used to express efficiency. The RER results and the tables provided by Peronnet et al. [32] were used to calculate the percentage of oxidation of the fats of each paddler in each of the cadences.

Blood lactate measurements were taken before, in the middle (4-min), and at the end (8-min) of each trial of sub-maximal intensity (45-55 and $65 \mathrm{spm}$ ). Blood lactate was assessed via a Lactate Scout 2 handheld blood lactate analyzer (SensLab GmbH, Leipzig, Germany), while lactate measurements were taken from blood extracted from a finger, with the first drop always being discarded to avoid contamination. Likewise, a Polar HR monitor and transmitter (Polar Electro, Lake Success, NY, USA) was used to measure HR, which was recorded during the incremental test and throughout the submaximal workload trials. 
The 10-point RPE scale [33] was used during the $\mathrm{VO}_{2}$ max test and at 4-min and 8-min of each submaximal trial (45-55 and $65 \mathrm{spm}$ ), and anyone other than researchers was forbidden from entering the laboratory in order for people's presence not to influence participants' RPE [34]. Verbal encouragement was given to all participants during the submaximal trials.

\subsection{Statistical Analyses}

Statistical data analyses were performed using the Statistical Package for the Social Sciences 24.0 (SPSS, Inc. Chicago, IL, USA), with descriptive statistics being calculated for each variable and expressed as mean \pm standard deviation (SD), and range (min-max). The Shapiro-Wilk test $(n<50)$ was conducted to determine the normality of the data, and the Levene test was used to check the uniformity of the variables analyzed. Differences between 4-min and 8-min tests for each variable in each cadence condition were assessed via a dependent t-test. $\mathrm{VO}_{2}$, blood lactate, RPE, HR, economy, gross efficiency, and RER were compared across different cadences using one-way ANOVA with the cadences as the fixed factor. Bonferroni post-hoc test was applied for pairwise comparisons among groups. Additionally, effect sizes were calculated using partial eta square and $\eta^{2} p$, although because this measure was likely to overestimate said effect sizes, values were interpreted according to that indicating that there was no effect if $0 \leq \eta^{2} p<0.05$; minimum effect if $0.05 \leq \eta^{2} p<0.26$; moderate effect if $0.26 \leq \eta^{2} p<0.64$; and a strong effect if $\eta^{2} p \geq 0.64$ [35]. Statistical significance for all analyses was set at $p<0.05$.

\section{Results}

Table 2 shows the data obtained in economy, gross efficiency, and RER. In contrast with RER, both economy and gross efficiency evidenced differences among cadences in the 8-min test $(p<0.05)$. More specifically, in 8-min, $45 \mathrm{spm}$ showed a lower economy and gross efficiency than the $65 \mathrm{spm}$ $(p<0.05)$. Additionally, in contrast with RER, which presented a higher value at 8-min than 4-min in 55 spm and 65 spm cadences $(p<0.05)$, there was no difference in economy and gross efficiency between 4 -min and 8-min in any of the 3 cadences $(p>0.05)$.

Table 2. Economy, gross efficiency, and RER variables of SUP Paddlers at 4-min and 8-min.

\begin{tabular}{|c|c|c|c|c|c|}
\hline & $45 \mathrm{spm}$ & $55 \mathrm{spm}$ & $65 \mathrm{spm}$ & $p$ & $\eta^{2} p$ \\
\hline \multicolumn{6}{|c|}{ Economy $\left(\mathrm{KJ} \cdot 1^{-1}\right)$} \\
\hline 4-min & $42.8 \pm 6.0$ & $40.5 \pm 9.4$ & $40.4 \pm 6.7$ & 0.238 & 0.150 \\
\hline 8-min & $45.3 \pm 5.7$ & $39.9 \pm 7.7$ & $38.1 \pm 5.3^{a}$ & 0.010 & 0.436 \\
\hline \multicolumn{6}{|c|}{ Gross Efficiency (\%) } \\
\hline 4-min & $12.7 \pm 2.2$ & $11.9 \pm 2.9$ & $11.9 \pm 2.2$ & 0.166 & 0.192 \\
\hline 8 -min & $13.4 \pm 2.3$ & $11.6 \pm 2.4$ & $11.0 \pm 1.6^{\mathrm{a}}$ & 0.012 & 0.430 \\
\hline \multicolumn{6}{|c|}{ RER } \\
\hline 4-min & $0.918 \pm 0.05$ & $0.950 \pm 0.065$ * & $0.951 \pm 0.030$ * & 0.206 & 0.187 \\
\hline $8-\min$ & $0.934 \pm 0.04$ & $0.964 \pm 0.053$ & $0.992 \pm 0.047$ & 0.081 & 0.280 \\
\hline
\end{tabular}

Data are shown as mean \pm standard deviation. 4-min and 8-min refer to the middle and the end of the test, respectively; $p$, Significant differences between cadences by one factor ANOVA (cadences); ${ }^{a}$, significant differences regarding $45 \mathrm{spm}$ using the Bonferroni test; ${ }^{*}$, significant differences between 4-min and 8-min using dependent $t$-test.

Table 3 depicts the results in $\mathrm{VO}_{2}, \mathrm{HR}$, Lactate, and $\mathrm{RPE}$ of each cadence. $\mathrm{VO}_{2}, \mathrm{HR}$, lactate, and RPE evidenced differences among cadences in the 8 -min test $(p<0.05)$. The cadence of $65 \mathrm{spm}$ presented a higher $\mathrm{VO}_{2}, \mathrm{HR}$, lactate, and RPE than $45 \mathrm{spm}$ in the 8-min test $(p<0.05)$. Moreover, lactate and RPE in $65 \mathrm{spm}$ presented higher value than $55 \mathrm{spm}$ in the 8-min test $(p<0.05)$. On the other hand, HR and RPE was higher at 8-min than 4-min in $55 \mathrm{spm}$ and $65 \mathrm{spm}$. However, at 8-min lactate presented a higher value than at $4-\mathrm{min}$ in $65 \mathrm{spm}(p<0.05)$. 
Table 3. $\mathrm{VO}_{2}, \mathrm{HR}$, Lactate, and RPE variables of SUP Paddlers at 4-min and 8-min.

\begin{tabular}{|c|c|c|c|c|c|}
\hline & $45 \mathrm{spm}$ & $55 \mathrm{spm}$ & $65 \mathrm{spm}$ & $p$ & $\eta^{2} p$ \\
\hline \multicolumn{6}{|c|}{$\mathrm{VO}_{2}\left(\mathrm{~mL} \cdot \mathrm{kg}^{-1} \cdot \mathrm{min}^{-1}\right)$} \\
\hline 4-min & $35.0 \pm 5.1$ & $37.3 \pm 6.5$ & $37.3 \pm 5.9$ & 0.224 & 0.158 \\
\hline $8-\min$ & $34.4 \pm 6.0$ & $38.6 \pm 5.2^{\mathrm{a}}$ & $38.7 \pm 5.9^{\mathrm{a}}$ & 0.020 & 0.415 \\
\hline \multicolumn{6}{|c|}{ HR (beats·min ${ }^{-1}$ ) } \\
\hline 4-min & $157.4 \pm 16.6^{*}$ & $159.8 \pm 19.7^{*}$ & $164.2 \pm 13.4$ * & 0.074 & 0.252 \\
\hline 8-min & $161.2 \pm 16.4$ & $168.1 \pm 15.1^{a}$ & $170.7 \pm 13.0^{\mathrm{a}}$ & 0.007 & 0.463 \\
\hline \multicolumn{6}{|c|}{ Lactate $\left(\mathrm{mmol} \mathrm{L}^{-1}\right)$} \\
\hline 4-min & $3.4 \pm 1.0$ & $3.9 \pm 1.5$ & $4.1 \pm 1.0 *$ & 0.171 & 0.192 \\
\hline 8 -min & $3.5 \pm 1.0$ & $4.2 \pm 1.2^{\mathrm{a}}$ & $5.3 \pm 1.8^{a, b}$ & 0.006 & 0.506 \\
\hline \multicolumn{6}{|c|}{ RPE } \\
\hline 4-min & $6.0 \pm 2.1$ & $6.2 \pm 1.5^{*}$ & $6.4 \pm 1.8^{*}$ & 0.461 & 0.077 \\
\hline 8 -min & $6.0 \pm 1.7$ & $6.9 \pm 1.4$ & $7.6 \pm 1.4^{\mathrm{a}, \mathrm{b}}$ & $<0.001$ & 0.618 \\
\hline
\end{tabular}

Data are shown as mean \pm standard deviation. 4-min and 8-min refer to the middle and the end of the test, respectively. $p$ : Significant differences between cadences by one-factor ANOVA (cadences); ${ }^{a}$, Significant differences regarding $45 \mathrm{spm}$ using the Bonferroni test; ${ }^{\mathrm{b}}$, significant differences regarding $55 \mathrm{spm}$ using the Bonferroni test; *, Significant differences between 4-min and 8-min using dependent $t$-test.

\section{Discussion}

The main aim of this study was to determine the influence of cadence $(45,55$, and $65 \mathrm{spm})$ on gross efficiency, economy, HR, blood lactate, RPE, and RER in an 8-min test in elite competitive male paddlers. The main finding of this study was that paddling gross efficiency and economy were higher at $45 \mathrm{spm}$ than at $65 \mathrm{spm}$, and RER was lower at $45 \mathrm{spm}$. HR and lactate were lower during the $45 \mathrm{spm}$ trial and likely reflected the lower $\mathrm{VO}_{2}$ and higher gross efficiency associated with this cadence. Movement efficiency, combined with maximum aerobic power and anaerobic threshold, are three physiological measures that together can be used to predict performance in endurance sports $[10,11,21,30,36]$. This efficiency of movement is influenced by the energy substrate used and the percentage of slow (more efficient) muscle fibers [37,38]. Since SUP is an endurance sport, energy-saving and, therefore, efficiency is an important factor in racing performance.

There are no other studies analyzing the influence of different stroke cadences on movement gross efficiency and economy in SUP. We found that paddling at $45 \mathrm{spm}$ was $13 \%$ and $17.5 \%$ more efficient and $12.9 \%$ and $16.9 \%$ more economical than at 55 and $65 \mathrm{spm}$, respectively. The upper body is generally accepted as having a greater proportion of fast-twitch fibers when compared to the lower body $[39,40]$. Interestingly, the energetically optimal cadence has been reported to be higher in a model with more fast-twitch fibers than a model with more slow-twitch fibers [41], consistent with predictions from the literature [42-44]. This would partially explain why higher cadences displayed worse gross efficiency values in the current study. Similarly, higher cadences may be related to greater instability, which would imply higher needs of muscle activation for postural control and would ultimately lead to higher energy consumption, and therefore, worse efficiency [45]. When compared to studies in other sports, our findings were in agreement with those of Neilsen et al. [46] and Jacobs et al. [20] in cycling, Gonzalez-Aramendi [24] in traditional rowing, and Kraaijenbrink et al. [25] in hand cycling, as all of them found that lower cadences were related to better efficiency and economy values. In contrast, Lucia et al. [21] and Mora-Rodriguez and Aguado-Jimenez [47] in cycling, or Goosey et al. [26] in hand cycling reported that higher cadences were more efficient and economical. These differences may be due to the competitive level of the sport according to the number of practitioners who perform the activity, the kind of exercise performed (upper vs. lower body), and the different protocol used to determinate the movement efficiency/economy (i.e., incremental vs. constant intensity test). 
In this regard, SUP is a relatively new sport and has a low level of professionalization when compared to other types of sport [27]. It can therefore be assumed that well-trained cyclists [47], world-class cyclists [21], or top-level athletes [26] have more training experience in their disciplines than SUP athletes (5.8 \pm 1.9 years). Longer training experience in athletes of consolidated disciplines may imply a greater volume of training over the years, which is known to produce various physiological adaptations related to efficiency and economy. Similarly, neuromotor recruitment can be improved by the greater volume of training on the part of experienced athletes [11]. Moreover, higher cadences appear to affect negatively the force effectiveness [48], which is a measure of the paddling technique. Higher cadences are believed to increase internal kinetic energy fluctuations (rotation of the extremities). Even if this energy flow can also be used as external work [49], it is likely associated with an increased oxygen cost and, therefore, it would affect efficiency and economy negatively. Higher cadences may also affect the inertial components of the paddling forces, which are related to the kinetic energy fluctuations, similar to what has been observed in cycling [50].

Another aspect to take into account in relation to efficiency and economy is the number of muscles involved in the specific activity, diffusion area, and diffusion distance [51-53]. Since the upper body is believed to have a greater proportion of fast-twitch fibers [39,40], it may explain the slower kinetics of $\mathrm{VO}_{2}$ and cardiac output in the transition from rest to exercise intensities of between $30-90 \%$ PPO in the upper body when compared to the lower body [39,54]. Lastly, the evaluation protocol used is another factor that should be considered when monitoring efficiency and economy. The duration of the exercise bouts during the examination may affect values, as protocols with the longer bouts [20] report a continuous decrease in efficiency in terms of time and cadence, and, in addition, the use of a minute 4 ramp protocol $[25,26,47]$ may underestimate steady-state $\mathrm{VO}_{2}$.

Interestingly, we found that the substrate utilization varied among cadences. When paddling at $45 \mathrm{spm}$ the percentage of fat used to obtain energy was $21.4 \%$ compared to $11.6 \%$ at $55 \mathrm{spm}$ and $2 \%$ at $65 \mathrm{spm}$ [32]. This means consuming twice ( $55 \mathrm{spm})$ and ten times $(65 \mathrm{spm})$ as much fat, respectively (Table 2). Considering that most races in the best SUP circuits in the world take about one hour, these differences in substrate utilization may imply that an efficient paddler will end the race with a higher amount of carbohydrates available [55,56]. This advantage in terms of availability of substrates may be of great importance in finishing a competition at high intensity [57]. The results obtained from our study reflect lower RER (greater fat utilization) with the $45 \mathrm{spm}$ cadence, which would allow paddlers to save on their most valuable energy substrate.

It is important to take into account that athletes have a naturally chosen cadence, which is usually the most economical [58]. This subconscious fine-tuning of movement biomechanics is referred to as self-optimization, which appears to be a physiological adaptation resulting from greater training experience [59]. In order to optimally recruit motor units, cadences may require specific training. This lack of familiarity with some cadences has been studied in cycling [60,61], and the results indicate that the most used cadences, compared to the unknown ones, are the ones that obtain the best results. However, this type of study with different cadences avoids the possible motor learning that may occur when exercising with several cadences. To allow for any possible motor learning effect on movement gross efficiency, it may be useful to add training for a period of time to the design of this type of study before evaluating gross efficiency [23].

We have to acknowledge several limitations. It is important to highlight the small sample size in this study. However, it is also true that it is very difficult to obtain larger samples in elite sports and in this case, in a new sport with a low level of professionalization [27]. Moreover, this study used a work rate of $75 \%$ of peak power, and so our results may not be applicable to higher or lower work rates. Likewise, we should take into account the cadence naturally selected by the paddlers, because as we have commented previously, it can influence the economy results. Therefore, individual athletes should try various cadences and drags to personally optimize economy. Since SUP racing is not performed at a constant work rate, we suspect that optimal cadence may vary depending on waves, 
wind, and other environmental conditions; having said this, the use of $45 \mathrm{spm}$ may be an effective cadence with which to compare other paddling speeds.

This study contributes to knowledge about paddlers' physiological response, besides also contributing to the good design of both race and training strategies. The limitations of extrapolating these data so as to put them into practice in the field are evident, as the differences between simulated laboratory practice and practice in the field in SUP mode have not yet been studied. One study made the same comparison for similar sports, such as kayaking, and concluded that the ergometer accurately simulates the physiological demands of kayaking (50). Future studies should contrast the differences between laboratory and field measurements in SUP.

\section{Conclusions}

International male SUP paddlers were most gross efficiency and economical when paddling at $45 \mathrm{spm}$ vs. 55 or $65 \mathrm{spm}$, as confirmed by lower RPE values in measurements made in a laboratory. Similarly, this gross efficiency and economy shown at $45 \mathrm{spm}$ implied a greater use of fat as an energy substrate. Those improvements may likely translate to faster paddling speed and greater endurance, and they may be helpful to coaches and athletes in determining optimal GE and economy, as these differences in competition are likely to yield meaningful improvement in performance.

\section{Practical Applications}

This study attempted to determine whether a low vs. high cadence would give rise to better energy gross efficiency and economy in paddlers participating in international competitions. The 45-stroke cadence was the most gross efficiency and economical one, in addition to obtaining lower psycho-physiological values than the other cadences. These results reinforce the idea that paddling at a low cadence can maximize sustainable energy production while minimizing metabolic stress. These paddlers could improve their performance in long-distance tests by paddling at a low cadence vs. a high cadence.

Author Contributions: Conceptualization, A.C.-B.; Data curation, A.C.-B. and B.G.-S.; Formal analysis, J.S.-C., A.V. and J.M.-A.; Investigation, J.M.-A.; Project administration, A.C.-B.; Software, B.G.-S.; Supervision, A.V. and J.M.-A.; Writing-Original draft, A.C.-B., J.S.-C. and J.M.-A.; Writing-Review \& editing, A.C.-B., J.S.-C., A.V., B.G.-S. and J.M.-A. All authors have read and agreed to the published version of the manuscript.

Funding: The authors declare no funding sources.

Acknowledgments: The authors thank the athletes and research assistants involved in this research for their participation, enthusiasm, and cooperation.

Conflicts of Interest: The authors declare no conflict of interest.

\section{References}

1. Ruess, C.; Kristen, K.; Eckelt, M.; Mally, F.; Litzenberger, S.; Sabó, A. Stand up paddle surfing-an aerobic workout and balance training. Procedia Eng. 2013, 60, 62-66. [CrossRef]

2. Hammer, S. Catch the wave of stand up paddling. Provid. J. 2011, 5, 3.

3. Schram, B.; Hing, W.; Climstein, M. A survey of injuries and medical conditions affecting stand-Up paddle surfboarding participants. Clin. J. Sport Med. 2010, 20, 144.

4. Schram, B.; Hing, W.; Climstein, M. Profiling the sport of stand-up paddle boarding. J. Sports Sci. 2015, 34, 937-944. [CrossRef]

5. SUPA Competition Rules-SUP Surfing. Available online: http://www.sup-australia.com/events/rules-supsurfing (accessed on 18 June 2020).

6. Mendez-Villanueva, A.; Bishop, D.J. Physiological aspects of surfboard riding performance. Sports Med. 2005, 35, 55-70. [CrossRef] [PubMed]

7. Schram, B. Stand up Paddle Boarding: An Analysis of a New Sport and Recreational Activity. Ph.D. Thesis, Bond University, Gold Coast, QLD, Australia, August 2015. 
8. Schram, B.; Hing, W.; Climstein, M. Laboratory- and field-based assessment of maximal aerobic power of elite stand-up paddle-board athletes. Int. J. Sports Physiol. Perform. 2016, 11, 28-32. [CrossRef] [PubMed]

9. Lucia, A.; Hoyos, J.; Chicharro, J.L. Preferred pedalling cadence in professional cycling. Med. Sci. Sports Exerc. 2001, 33, 1361-1366. [CrossRef]

10. Lucia, A.; Hoyos, J.; Pérez, M.; Santalla, A.; Chicharro, J.L. Inverse relationship between VO2max and economy/efficiency in world-class cyclists. Med. Sci. Sports Exerc. 2002, 34, 2079-2084.

11. Santalla, A.; Naranjo, J.; Terrados, N. Muscle efficiency improves over time in world-class cyclists. Med. Sci. Sports Exerc. 2009, 41, 1096-1101. [CrossRef]

12. Bransford, D.R.; Howley, E.T. Oxygen cost of running in trained and untrained men and women. Med. Sci. Sports 1977, 9, 41-44. [CrossRef]

13. Conley, D.L.; Krahenbuhl, G.S.; Burkett, L.N.; Millar, A.L. Physiological correlates of female road racing performance. Res. Q. Exerc. Sport 1981, 52, 441-448. [CrossRef]

14. Krahenbuhl, G.S.; Pangrazi, R.P. Characteristics associated with running performance in young boys. Med. Sci. Sports Exerc. 1983, 15, 486-490. [CrossRef] [PubMed]

15. Daniels, J.T. A physiologist's view of running economy. Med. Sci. Sport Exerc. 1985, 17, 332-338.

16. Green, J.M.; McLester, J.R.; Crews, T.R.; Wickwire, P.J.; Pritchett, R.C.; Lomax, R. RPE association with lactate and heart rate during high-intensity interval cycling. Med. Sci. Sports Exerc. 2006, 38, 167-172. [CrossRef] [PubMed]

17. Hausswirth, C.; Lehénaff, D. Physiologycal demands of running during long distance runs and triathlons. Sport Med. 2001, 31, 679-689. [CrossRef] [PubMed]

18. Mooses, M.; Mooses, K.; Haile, D.W.; Durussel, J.; Kaasik, P.; Pitsiladis, Y.P. Dissociation between running economy and running performance in elite Kenyan distance runners. J. Sport Sci. 2015, 33, 136-144. [CrossRef]

19. Bassett, D.R. Limiting factors for maximum oxygen uptake and determinants of endurance performance. Med. Sci. Sports Exerc. 2000, 32, 70. [CrossRef]

20. Jacobs, R.D.; Berg, K.E.; Slivka, D.R.; Noble, J.M. The effect of cadence on cycling efficiency and local tissue oxygenation. J. Strength Cond. Res. 2013, 27, 637-642. [CrossRef]

21. Lucia, A.; Juan, A.F.S.; Montilla, M.; CaNete, S.; Santalla, A.; Earnest, C.P.; Perez, M. In professional road cyclists, low pedaling cadences are less efficient. Med. Sci. Sports Exerc. 2004, 36, 1048-1054. [CrossRef]

22. Vincent, H.K.; Massengill, C.; Harris, A.; Chen, C.; Wasser, J.G.; Bruner, M.; Vincent, K.R. Cadence impact on cardiopulmonary, metabolic and biomechanical loading during downhill running. Gait Posture 2019, 71, 186-191. [CrossRef]

23. Hafer, J.F.; Brown, A.M.; DeMille, P.; Hillstrom, H.J.; Garber, C.E. The effect of a cadence retraining protocol on running biomechanics and efficiency: A pilot study. J. Sports Sci. 2014, 33, 724-731. [CrossRef] [PubMed]

24. Gonzalez Aramendi, J. Olympic rowing and traditional rowing: Biomechanical, physiological and nutritional aspects. Arch. Med. Deport. 2014, 31, 51-59.

25. Kraaijenbrink, C.; Vegter, R.; Hensen, A.H.R.; Wagner, H.; Van Der Woude, L.H.V. Different cadences and resistances in sub-maximal synchronous handcycling in able-bodied men: Effects on efficiency and force application. PLoS ONE 2017, 12, e0183502. [CrossRef] [PubMed]

26. Goosey-Tolfrey, V.L.; Alfano, H.; Fowler, N. The influence of crank length and cadence on mechanical efficiency in hand cycling. Graefe's Arch. Clin. Exp. Ophthalmol. 2007, 102, 189-194. [CrossRef]

27. Schram, B.; Hing, W.; Climstein, M.; Furness, J. A performance analysis of a stand-up paddle board marathon race. J. Strength Cond. Res. 2017, 31, 1552-1556. [CrossRef] [PubMed]

28. Fernández-López, J.R.; Cámara, J.; Maldonado, S.; Rosique-Gracia, J.; Maldonado-Martín, S. The effect of morphological and functional variables on ranking position of professional junior Basque surfers. Eur. J. Sport Sci. 2013, 13, 461-467. [CrossRef]

29. Machado, F.A.; Kravchychyn, A.C.P.; Peserico, C.S.; Da Silva, D.F.; Mezzaroba, P.V. Incremental test design, peak 'aerobic' running speed and endurance performance in runners. J. Sci. Med. Sport 2013, 16, 577-582. [CrossRef]

30. Moseley, L.; Jeukendrup, A.E. The reliability of cycling efficiency. Med. Sci. Sports Exerc. 2001, 33, 621-627. [CrossRef]

31. Weir, J.B.V. New methods for calculating metabolic rate with special reference to protein metabolism. J. Physiol. 1949, 109, 1-9. [CrossRef] 
32. Péronnet, F.; Massicotte, D. Table of nonprotein respiratory quotient: An update. Can. J. Sport Sci. 1991, 16, 23-29.

33. Borg, G. Borg's Perceived Exertion and Pain Scales; Human Kinetics: Champaign, IL, USA, 1998; pp. 27-38.

34. Carnes, A.J.; Barkley, J.E.; Williamson, M.; Sanders, G. The presence of a familiar peer does not affect intensity or enjoyment during treadmill exercise in male distance runners or non-runners. J. Athl. Enhanc. 2013, 2, 4-9. [CrossRef]

35. Ferguson, C.J. An effect size primer: A guide for clinicians and researchers. Prof. Psychol. Res. Pr. 2009, 40, 532-538. [CrossRef]

36. Hagberg, J.M.; Moore, G.E.; Ferrell, R.E. Specific genetic markers of endurance performance and VO2max. Exerc. Sport Sci. Rev. 2001, 29, 15-19. [CrossRef] [PubMed]

37. Mogensen, M.; Bagger, M.; Pedersen, P.K.; Fernstrom, M.; Sahlin, K. Cycling efficiency in humans is related to low UCP3 content and to type I fibres but not to mitochondrial efficiency. J. Physiol. 2006, 571, 669-681. [CrossRef]

38. Horowitz, J.F.; Sidossis, L.S.; Coyle, E.F. High efficiency of type I muscle fibers improves performance. Int. J. Sports Med. 1994, 15, 152-157. [CrossRef]

39. Koppo, K.; Bouckaert, J.; Jones, A.M. Oxygen uptake kinetics during high-intensity arm and leg exercise. Respir. Physiol. Neurobiol. 2002, 133, 241-250. [CrossRef]

40. Sanchis-Moysi, J.; Idoate, F.; Olmedillas, H.; Guadalupe-Grau, A.; Alayón, S.; Carreras, A.; Dorado, C.; Calbet, J.A.L. The upper extremity of the professional tennis player: Muscle volumes, fiber-type distribution and muscle strength. Scand. J. Med. Sci. Sports 2009, 20, 524-534. [CrossRef]

41. Umberger, B.R.; Gerritsen, K.G.; Martin, P.E. Muscle fiber type effects on energetically optimal cadences in cycling. J. Biomech. 2006, 39, 1472-1479. [CrossRef]

42. Woledge, R.C. The energetics of tortoise muscle. J. Physiol. 1968, 197, 685-707. [CrossRef]

43. Gibbs, C.L.; Gibson, W.R. Isoprenaline, propranolol, and the energy output of rabbit cardiac muscle. Cardiovasc. Res. 1972, 6, 508-515. [CrossRef]

44. Wendt, I.; Gibbs, C. Energy production of rat extensor digitorum longus muscle. Am. J. Physiol. Content 1973, 224, 1081-1086. [CrossRef] [PubMed]

45. Finatto, P.; Silva, E.S.D.; Okamura, A.B.; Almada, B.P.; Oliveira, H.B.; Peyré-Tartaruga, L.A. Pilates training improves 5-km run performance by changing metabolic cost and muscle activity in trained runners. PLoS ONE 2018, 13, e0194057.

46. Nielsen, J.; Hansen, E.A. Pedalling rate affects endurance performance during high-intensity cycling. Graefe's Arch. Clin. Exp. Ophthalmol. 2004, 92, 114-120. [CrossRef] [PubMed]

47. Mora-Rodriguez, R.; Aguado-Jimenez, R. Performance at high pedaling cadences in well-trained cyclists. Med. Sci. Sports Exerc. 2006, 38, 953-957. [CrossRef] [PubMed]

48. Leirdal, S.; Ettema, G. The relationship between cadence, pedalling technique and gross efficiency in cycling. Graefe's Arch. Clin. Exp. Ophthalmol. 2011, 111, 2885-2893. [CrossRef]

49. Ettema, G.J.C.; Lorås, H.W. Efficiency in cycling: A review. Graefe's Arch. Clin. Exp. Ophthalmol. 2009, 106, 1-14. [CrossRef]

50. Ettema, G.J.C.; Lorås, H.; Leirdal, S. The effects of cycling cadence on the phases of joint power, crank power, force and force effectiveness. J. Electromyogr. Kinesiol. 2009, 19, e94-e101. [CrossRef]

51. Nagle, F.J.; Richie, J.P.; Giese, M.D. VO2max responses in separate and combined arm and leg air-braked ergometer exercise. Med. Sci. Sports Exerc. 1984, 16, 563-566. [CrossRef]

52. Sawka, M.N. 6 Physiology of upper body exercise. Exerc. Sport Sci. Rev. 1986, 14, 175-212. [CrossRef]

53. Calbet, J.A.L.; De Paz, J.A.; Garatachea, N.; De Vaca, S.C.; Chavarren, J.; Vallejo, N.G. Anaerobic energy provision does not limit Wingate exercise performance in endurance-trained cyclists. J. Appl. Physiol. 2003, 94, 668-676. [CrossRef] [PubMed]

54. Koga, S.; Shiojiri, T.; Shibasaki, M.; Fukuba, Y.; Kondo, N.; Fukuoka, Y. Kinetics of oxygen uptake and cardiac output at onset of arm exercise. Respir. Physiol. 1996, 103, 195-202. [CrossRef]

55. Lundsgaard, A.-M.; Fritzen, A.M.; Kiens, B. Molecular regulation of fatty acid oxidation in skeletal muscle during aerobic exercise. Trends Endocrinol. Metab. 2018, 29, 18-30. [CrossRef]

56. Hearris, M.A.; Hammond, K.M.; Fell, J.M.; Morton, J.P. Regulation of muscle glycogen metabolism during exercise: Implications for endurance performance and training adaptations. Nutrients 2018, 10, 298. [CrossRef] [PubMed] 
57. Fritzen, A.M.; Lundsgaard, A.-M.; Kiens, B. Dietary fuels in athletic performance. Annu. Rev. Nutr. 2019, 39, 45-73. [CrossRef]

58. Moore, L.J.; Vine, S.J.; Wilson, M.R.; Freeman, P. The effect of challenge and threat states on performance: An examination of potential mechanisms. Psychophysiology 2012, 49, 1417-1425. [CrossRef] [PubMed]

59. Moore, I.S. Is there an economical running technique? A review of modifiable biomechanical factors affecting running economy. Sport. Med. 2016, 46, 793-807. [CrossRef]

60. Bernard, T.; Vercruyssen, F.; Grego, F.; Hausswirth, C.; Lepers, R.; Vallier, J.-M.; Brisswalter, J.; Vleck, V. Effect of cycling cadence on subsequent $3 \mathrm{~km}$ running performance in well trained triathletes. Br. J. Sports Med. 2003, 37, 154-159. [CrossRef]

61. Marsh, A.P.; Martin, P.; Foley, K.O. Effect of cadence, cycling experience, and aerobic power on delta efficiency during cycling. Med. Sci. Sports Exerc. 2000, 32, 1630-1634. [CrossRef]

(C) 2020 by the authors. Licensee MDPI, Basel, Switzerland. This article is an open access article distributed under the terms and conditions of the Creative Commons Attribution (CC BY) license (http://creativecommons.org/licenses/by/4.0/). 